\title{
CeRNA Expression Profiling Identifies KIT-Related circRNA- miRNA-mRNA Networks in Gastrointestinal Stromal Tumour
}

\author{
Ning Jia ${ }^{1,2 t}$, Hanxing Tong ${ }^{3 \dagger}$, Yong Zhang ${ }^{3 t}$, Hiroshi Katayama ${ }^{4}$, Yuan Wang ${ }^{1}$, Weiqi Lu ${ }^{3}$, \\ Sumei Zhang ${ }^{1 *}$ and Jin Wang ${ }^{2 *}$ \\ ${ }^{1}$ Laboratory of Molecular Biology and Department of Biochemistry, Anhui Medical University, Hefei, China, ${ }^{2}$ Shanghai \\ Public Health Clinical Center, Fudan University, Shanghai, China, ${ }^{3}$ Department of General Surgery, Zhongshan Hospital, \\ Fudan University, Shanghai, China, ${ }^{4}$ Department of Molecular Oncology, Okayama University Graduate School of Medicine, \\ Dentistry and Pharmaceutical Sciences, Okayama, Japan
}

OPEN ACCESS

Edited by:

Yujing Li,

Emory University,

United States

Reviewed by:

Graziella Curtale,

The Scripps Research Institute,

United States

Feng Wang,

Emory University School of Medicine,

United States

*Correspondence:

Sumei Zhang

379236778@qq.com

Jin Wang

wjncityu@yahoo.com

these authors have contributed equally to this work

Specialty section: This article was submitted to RNA,

a section of the journal

Frontiers in Genetics

Received: 13 December 2018

Accepted: 09 August 2019

Published: 10 September 2019

Citation:

Jia N, Tong $H$, Zhang $Y$, Katayama $H$,

Wang Y, Lu W, Zhang S and Wang J (2019) CeRNA Expression

Profiling Identifies KIT-Related circRNA-miRNA-mRNA Networks in Gastrointestinal Stromal Tumour.

Front. Genet. 10:825.

doi: 10.3389/fgene.2019.00825
Gastrointestinal stromal tumours (GISTs) are the most common human sarcomas and are typically located in the stomach or small intestine. Although circular RNAs (circRNAs) reportedly play vital roles in tumour oncogenesis and progression, the molecular basis of the aggressive tumour biology of these circRNAs in GISTs remains unclear. In this study, we applied SBC ceRNA microarrays to screen for tumour-specific circRNA profiles in GISTs and identified that a total of 5,770 circRNAs and 1,815 mRNAs were differentially expressed in GISTs. Three significantly differential circRNAs (circ_0069765, circ_0084097, and circ_0079471) and their host genes (KIT, PLAT, and ETV1) were also verified in 68 pairs of GISTs and adjacent normal gastrointestinal tissues by qRT-PCR. A GIST-specific circRNA-miRNA-mRNA regulatory network analysis demonstrated that the specific KITrelated regulatory networks involved the three circRNAs, the circRNA host genes and three miRNAs (miR-142-5p, miR-144-3p and miR-485-3p), which may be key regulators of GISTs that could serve as molecular biomarkers and potential therapeutic targets for this malignant disease.

Keywords: circRNAs, KIT, PLAT, ETV1, regulatory networks analysis

\section{INTRODUCTION}

As one of the most common non-epithelial neoplasms, gastrointestinal stromal tumours (GISTs) are located in the stomach (55.6\%), small intestine (31.8\%), colon and rectum $(6.0 \%)$, and oesophagus and abdominal cavity (6.2\%) and have various clinical features ranging from asymptomatic to nonspecific abdominal discomfort, pain, haemorrhage and tumour abdominal (Joensuu et al., 2012); the incidence of GISTs is 10-15 cases per million per year in 19 countries (Soreide et al., 2016). It is not necessary for GIST patients to exhibit liver metastasis or intraperitoneal dissemination to perform an assessment of the tumour risk. However, clinicopathological factors, including the tumour size, mitotic count and anatomical location, were associated with cancer patient survival (Fletcher et al., 2002; Markku Miettinen and Jerzy Lasota, 2006; Joensuu, 2008), and complete surgical resection remains the primary treatment method for localized GISTs (Ho and Blanke, 2011). GISTs can be characterized by the expression of CD117 or PDGFRA protein in neoplastic cells, and a gain-of-function mutation may exist in 
the type III receptor tyrosine kinase gene (c-KIT or PDGFR- $\alpha$ ) at the genetic level (Hirota et al., 1998; Heinrich et al., 2003b). KIT is a receptor tyrosine kinase that is upregulated in the interstitial cells of Cajal, which are pacemakers responsible for digestive movement (Chi et al., 2010). KIT mutations frequently occur in exons 9, 11, 13 and 17 (Heinrich et al., 2003a; Corless et al., 2004) and play a vital role in GIST pathogenesis (Mazur and Clark, 1983; Hirota et al., 1998). In addition, a PDGFR- $\alpha$ mutation, which is present in $1 / 3$ of KIT-negative GIST patients, mainly affects exons 12, 14 and 18 and can induce tyrosine kinase autophosphorylation, activate signalling molecules containing $\mathrm{SH} 2$ domains, and initiate various cancer-related pathways (Wozniak et al., 2012).

Additionally, deregulated circular RNAs (circRNAs) were investigated in acute myeloid leukaemia, breast cancer, gastric cancer, and prostate cancer (Patop and Kadener, 2018; Xia et al., 2018) and found to be involved in a variety of tumour-specific progression events, such as proliferation, invasion and metastasis (Li F et al., 2015; Li J et al., 2015; Wilusz, 2017; Yang et al., 2018; Patop and Kadener, 2018). These deregulated circRNAs exhibit cell- or tissue-specific expression, exist in a steady state on tissues, in the cellular nucleus and cytosol, on extracellular exosomes, and in body fluid and may serve as potential biomarkers of cancer (Gao and Zhao, 2018). Several deregulated circRNAs have been reported to contribute to promoting cell proliferation, such as circPVT1 in gastric tumours, circABCB10 in breast tumours and circBANP in colon tumours (Patop and Kadener, 2018). The downregulation of circITCH was also observed in bladder carcinoma, oesophageal squamous cell carcinoma, lung cancer, colon and rectal cancer and hepatocellular carcinoma (Patop and Kadener, 2018). circRNAs, which have a head-totail connected ring structure of exon or intron cyclization, are generated from pre-mRNAs (Wilusz, 2018) and play a sponge role by absorbing microRNAs for binding to the miRNAs of target genes, which could be indirectly influenced by circRNAs forming competing endogenous RNA (ceRNA) networks with circRNAs (Kim et al., 2009). The overexpression of circITCH passively modulated diverse tumour cellular processes by binding miR-17 via specific miRNA-binding sites, which had evident effects on the aggressive biological behaviours mediated by the circITCH/miR-17, miR-224/p21, and PTEN axis (Yang et al., 2018). We previously revealed that the differentially expressed circRNAs (circ_0062019 and circ_0057558) and the host gene SLC19A1 of circ_0062019 could be used as potential novel biomarkers of prostate cancer (Xia et al., 2018). However, to note, no altered circRNAs have been reported in GISTs, and we still lack adequate in-depth knowledge about the biological function of circRNAs in GISTs.

In this study, we first analysed the ceRNA expression profile in gastrointestinal stromal tumour using high-throughput circRNA gene microarray and verified the differential circRNAs in GISTs by qRT-PCR. Our exploration of the circRNA-miRNA-mRNA network could help by adding a new dimension to the study of the molecular mechanisms of GISTs and provide new directions for GIST diagnosis and treatment.

\section{MATERIALS AND METHODS}

\section{Patients and Specimens}

This study included patients with GIST who underwent partial or complete resection between Sept 2012 and Oct 2017 at Shanghai Public Health Clinical Center, Fudan University, China. The study was approved by the Medical Ethics Commission of Shanghai Public Health Clinical Center. All patients had understood all aspects of the informed consent and signed the informed consent forms before undergoing surgeries. During the operation, 68 pairs of GIST and adjacent normal gastrointestinal tissue samples were collected from obvious lesions and the corresponding gastric or intestinal tissues, which were 1-3 centimetre distant from the tumour edge and contained no obvious cancer cells. After removal from the body, the fresh samples were rapidly intensively chilled in liquid nitrogen within $5 \mathrm{~min}$ of excision to avoid degradation. Then, the frozen specimens were stored in a $-80^{\circ} \mathrm{C}$ refrigerator. All enrolled patients were diagnosed for the first time through a pathological examination before undergoing surgical resection. The definitive diagnosis of all cases required tissue biopsy, which relied on endoscopic ultrasound-guided fine-needle aspiration. The tumour histological grading were based on malignancy risk stratification of the gastrointestinal stromal cell tumours by tumour size, mitotic count, and location (Markku Miettinen and Jerzy Lasota, 2006).

\section{Cell Line, Plasmid and Cell Transfection}

The human gastrointestinal stromal tumour cell lines GIST-T1 and GIST-882 were obtained from the American Type Culture Collection (ATCC, Manassas, VA, USA). The GIST-T1 cells were cultured in Mcoy5A's medium, and the GIST-882 cells were cultured in Dulbecco's modified Eagle medium (DMEM) supplemented with $10 \%(\mathrm{v} / \mathrm{v})$ foetal bovine serum (FBS) (HyClone, Logan, UT, USA) under the culture conditions of $37^{\circ} \mathrm{C}$ and $5 \% \mathrm{CO}_{2}$. A circ_0084097 and an NC control pLCDH-ciR empty vector were synthesized by Geneseed Biotech Co. Ltd. (Guangzhou, China) and transfected into the GIST-T1 cells by using Lipofectamine 2000 reagent (Life Technologies Corporation, Carlsbad, CA, USA) following the manufacturer's protocol. The transfection efficiency was assessed using qRT-PCR.

\section{RNA Purification and SBC ceRNA Microarrays}

The total RNA was isolated and purified with TRIzol reagent (Invitrogen, Carlsbad, CA, USA) and a TIANGEN total RNA Isolation Kit (TIANGEN, Beijing, China) according to the manufacturer's protocol. The isolated RNAs were stored at $-80^{\circ} \mathrm{C}$. The RNA was qualified, and the RNA integrity number was determined by an Agilent 2100 bioanalyser, while the RNA concentration was analysed using a NanoDrop-2000 spectrophotometer (NanoDrop, USA). For the ceRNA microarray, the included RNA samples were obtained from 3 pairs of GIST and adjacent normal gastrointestinal 
tissue samples. cRNA was synthesized and amplified with an Agilent Low Input Quick Amp WT Labeling Kit (Santa Clara, CA, US) and can be labelled by cyanine 3-labelled CTP with T7 RNA polymerase. The labelled cRNA was purified by an RNeasy mini kit (Qiagen, USA) and loaded onto SBC Human $\left(4^{\star} 180 \mathrm{~K}\right)$ ceRNA microarrays including 88,371 circRNAs and 18,853 mRNAs (Shanghai Biotechnology corporation, Shanghai, China). The signals were scanned by an Agilent G2565CA Microarray Scanner. The raw data were obtained by Agilent Feature Extraction (v10.7). After normalization of the raw data with $\mathrm{R}$ software, the differentially expressed mRNAs and circRNAs were filtrated according to the fold change and Student t-test. The normalized signal value is the value calculated by $\log 2$. All ceRNAs with a fold change $(F C) \geq \pm 2$, a p-value $<0.05$ and intensity $>7.0$ were included for further statistical analysis. The complete ceRNA array datasets were deposited in the Gene Expression Omnibus (GEO) database under accession number GSE131481.

\section{Regulatory Network and Pathway Analysis of the Differential mRNAs and the Host Genes of the Differential circRNAs in GISTs}

To further investigate the functions of these differential mRNAs in GISTs, the functions of the differential genes were annotated with GO and KEGG pathway analyses (Xia et al., 2018). CircInteractome (https://circinteractome.nia.nih.gov/) was used to predict the putative miRNAs of the three circRNAs and the potential circRNA/miRNA interaction (Dudekula et al., 2016). Targetscan7.2 (https://circinteractome.org./ vert_72) was used to predict the targeted miRNAs of the three host genes. We overlapped the two predicted results. Finally, we selected the top miRNAs with the highest context scores ( score $>85$ ) to establish a circRNA-miRNA-host gene network, which was illustrated by Cytoscape3.5.

\section{Quantitative Real-Time Polymerase Chain Reaction (qRT-PCR) Analysis of the Differentially Expressed circRNAs and Their Host Genes in GISTs}

In total, 3 circRNAs were chosen for experimental validation by qRT-PCR. As an exoribonuclease, RNase R can only act on RNA from its 3' to 5' end but does not degrade circRNA (Suzuki et al., 2006). Therefore, to distinguish the expression between the linear mRNA and circRNA, total RNAs were incubated for $20 \mathrm{~min}$ at $37^{\circ} \mathrm{C}$ with or without RNase $\mathrm{R}$ (Epicentre Technologies, Madison, WI), and the resulting RNAs were purified using an RNAsimple Total RNA Kit (Tiangen, Beijing, China) and transcribed into cDNA. The cDNAs were synthesized with reverse transcriptase using a PrimeScript ${ }^{\mathrm{TM}}$ RT reagent Kit with gDNA Eraser (TaKaRa). The PCR comprised 50 ng cDNA, $10 \mu$ of 2 x PCR Master mix (SYBR Premix Ex Taq ${ }^{\mathrm{TM}}$ II kit) (TaKaRa), $0.8 \mu$ l primer forward $(10 \mu \mathrm{M}), 0.8 \mu \mathrm{l}$ primer reverse $(10 \mu \mathrm{M})$, and $0.4 \mu \mathrm{l}$ of ROX reference Dye and was performed on an ABI ViiA 7 (Applied Biosystems, DE, USA) as follows: denaturation at $95^{\circ} \mathrm{C}$ for 10 min, amplification at $95^{\circ} \mathrm{C}$ for $15 \mathrm{~s}$ over 40 cycles, followed by annealing and extension at $60^{\circ} \mathrm{C}$ for $1 \mathrm{~min}$. The results of the relative expression levels were obtained by calculating the raw data using the $2^{-\Delta \Delta \mathrm{Ct}}$ method. $18 \mathrm{~S}$ rRNA served as an internal control for the normalization. The numbers of exons and exact sequences of circ_0084097 produced from PLAT, circ_0069765 from KIT, and circ_0079471 from ETV1 were validated by Sanger sequencing. All the primers for circ_0084097, circ_0069765, and circ_0079471 were designed by Shanghai Biotechnology corporation and shown in Tables S1 and S2.

\section{Statistical Analysis}

To compare the GIST and adjacent normal gastrointestinal tissue samples, the significance of the relative quantification validation was conducted by Student t-test for the paired analysis. All tests were 2 -sided, and $\mathrm{p}<0.05$ was regarded as statistical significance. The data were analysed with Statistical Program for Social Sciences (SPSS) 16.0 software (SPSS, Chicago, IL, USA).

\section{RESULTS}

\section{Differentially Expressed mRNAs and circRNAs in GISTs}

The characteristics of the GIST patient population and the clinical details of the three samples from the GIST patients chosen for the SBC ceRNA arrays are shown in Table S3. The ceRNA arrays were performed to investigate the differentially expressed mRNAs and circRNAs in GISTs. Volcano plots were used to present the significant differences in the extracted data between the GIST and adjacent normal gastrointestinal tissue samples and show the expressed difference in mRNAs (Figure S1A) and circRNAs (Figure S1B) between the GIST and adjacent tissues. Based on the differences in their expression levels, hierarchical clustering showed the differentially expressed mRNA (Figure 1A) and circRNA (Figure 1B) expression profile among 3 pairs of GIST and adjacent normal gastrointestinal tissue samples. In total, 1,815 mRNAs (839 upregulated mRNAs and 976 downregulated mRNAs) (Table 1) and 5,770 circRNAs (3,122 upregulated circRNAs and 2,648 downregulated circRNAs) (Table 2) were differentially expressed between the GIST and adjacent normal gastrointestinal tissue samples $(\mathrm{p}<0.05$ and $\mathrm{FC} \geq \pm 2$ ). After screening the differentially expressed $m$ RNAs by retrieving the GEO database (GSE112) and utilizing GEO2R in analysing the array data (Table S4), Venn diagrams were generated to show the 387 common differentially expressed genes (DEGs) selected in our array and GEO dataset GSE112 (Figure 1C). Finally, 95 DEGs were also identified as the host genes of DEcircRNAs in GISTs. In total, 54 circRNA host genes were upregulated, and 41 DEcircRNA host genes were downregulated in the GIST tumour tissues from these three GISTs patients, which was consistent with the expression level of the circRNAs ( $p<0.05$ and FC $\geq \pm 2$ ) (Figure $1 \mathrm{D}$ and Table 3 ). 
A

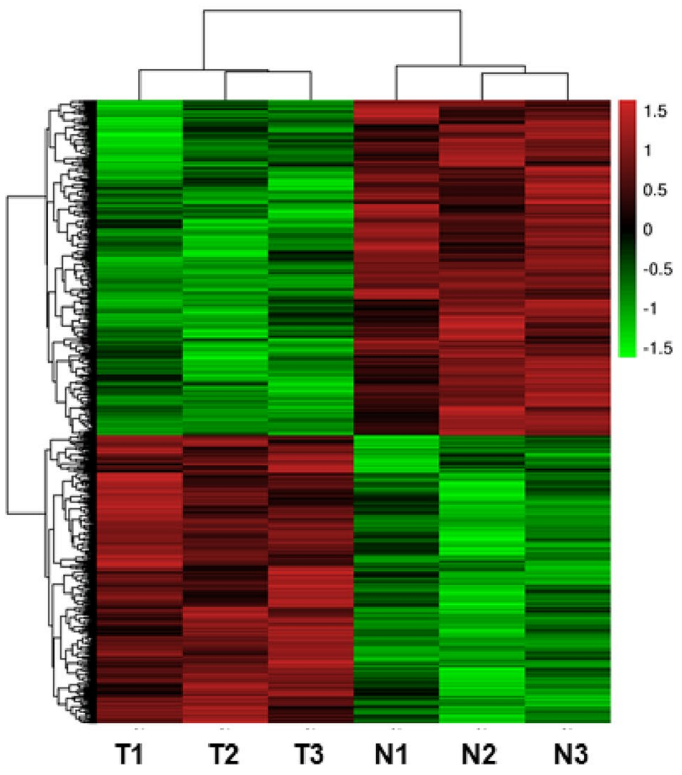

C

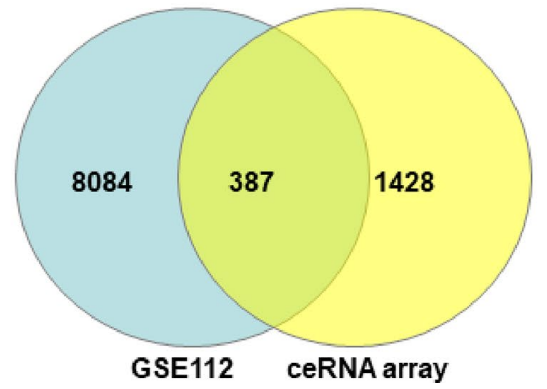

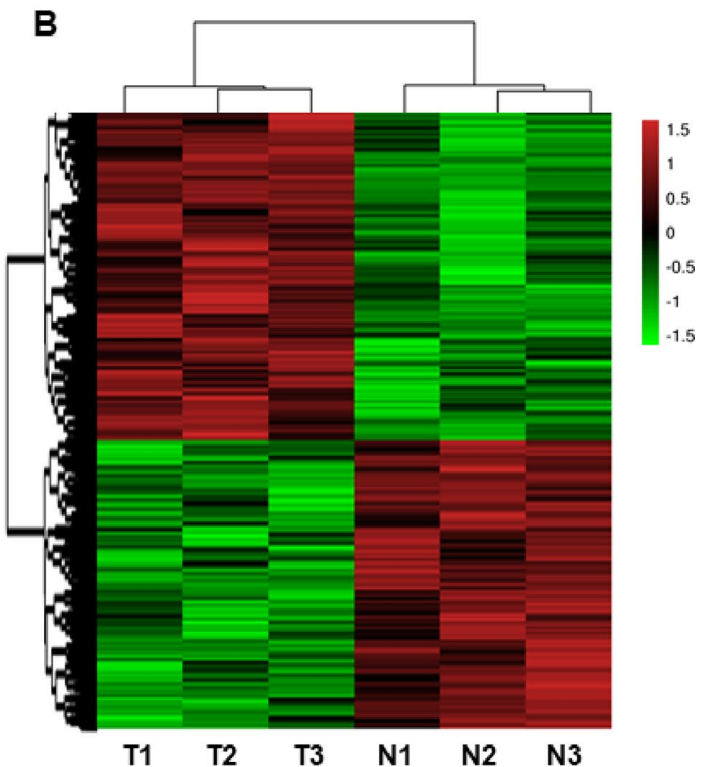

D

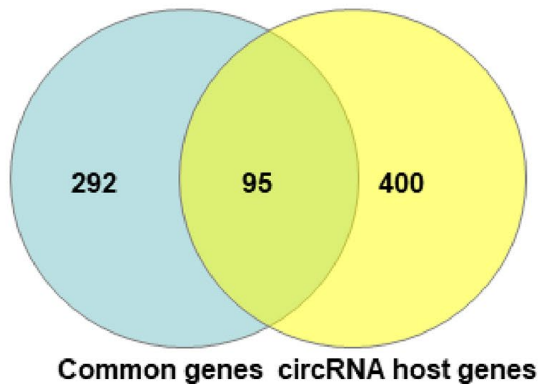

FIGURE 1 | Heatmaps and Venn Diagrams showing the differential mRNAs, circRNAs and their host genes in GISTs. Heat maps of the differentially expressed mRNAs (A) and circRNAs (B). Venn Diagrams showing that the common 387 mRNAs (C) were from differential mRNAs in the GEO dataset (GSE112) and our ceRNA array, and 95 common mRNAs were from overlapped 387 genes and differently expressed circRNA host genes in our ceRNA array (D).

\section{Functional Pathway Analysis of Differential mRNAs and circRNA Host Genes in GISTs}

Subsequently, a Kyoto Encyclopedia of Genes and Genomes (KEGG) analysis of these differentially expressed mRNAs and the host genes of the differential circRNAs in GISTs was performed to determine the top 5 pathways of the differential mRNAs, which included Biosynthesis of unsaturated fatty acids, Vitamin B6 metabolism, Notch signalling pathway, Dilated cardiomyopathy, ABC transporters and Hypertrophic cardiomyopathy (HCM) (Figure 2A); several circRNA host genes were enriched in the pathways of One carbon pool by folate, D-Glutamine and D-glutamate metabolism, ECMreceptor interaction, Adherens junction, and Nicotinate and nicotinamide metabolism (Figure 2B). Moreover, several common pathways involved the differentially expressed mRNAs and host genes of differential circRNAs in GISTs, including vascular smooth muscle contraction, Notch signalling pathway, nicotinate and nicotinamide metabolism, N-Glycan biosynthesis, hypertrophic cardiomyopathy (HCM), focal adhesion ECM-receptor interaction, Dilated cardiomyopathy, axon guidance and Arrhythmogenic right ventricular cardiomyopathy (ARVC).

\section{KIT-Related circRNA-miRNA-mRNA Regulatory Network Analysis in GISTs}

Among ceRNA expression profiling in GISTs, we found three circRNAs (circ_0069765, cir_0084097, and circ_0079471) and their host genes (KIT, PLAT, and ETV1) were up-regulated in GISTs. The molecular analysis of KIT becomes one of the two gold standards of diagnosis in GISTs. Mutation in the KIT gene is the key oncogenic drivers in the majority of GISTs (Wu et al., 2019), which is also potentiated by a positive feedback circuit that involves the ETS transcription factor ETV1 (Duensing, 2015; Wu et al., 2019). Besides, PLAT (TissueType Plasminogen Activator) as a node with VEGFC, PGF and $\mathrm{CHD} 7$ in the functional networks was also verified to be significantly enriched in blood vessel development involved in the tissue specificity of GISTs (Ma et al., 2018), which pushed us to analyze KIT related circRNA-miRNA-mRNA regulatory network in GISTs. Thus, three circRNAs derived from above 
TABLE 1 | Partially differentially expressed mRNAs in GIST.

\begin{tabular}{|c|c|c|c|}
\hline Gene Symbol & $\begin{array}{l}\text { Gene bank } \\
\text { Accession No }\end{array}$ & Fold change & $p$-values \\
\hline MC4R & NM_005912 & 518.09 & 0.031 \\
\hline F2RL2 & NM_004101 & 312.59 & 0.032 \\
\hline LY6H & NM_001130478 & 205.12 & 0.008 \\
\hline NPPC & NM_024409 & 141.15 & 0.001 \\
\hline FBN2 & NM_001999 & 133.50 & 0.019 \\
\hline OBSCN & NM_001271223 & 132.13 & 0.000 \\
\hline PTPRH & NM_002842 & 124.36 & 0.000 \\
\hline ASTN1 & NM_004319 & 112.92 & 0.027 \\
\hline SCG5 & NM_001144757 & 102.57 & 0.010 \\
\hline ITGA10 & NM_003637 & 94.89 & 0.006 \\
\hline TBX5 & NM_000192 & 93.62 & 0.037 \\
\hline PRKCQ & NM_006257 & 92.00 & 0.001 \\
\hline ANO1 & NM_018043 & 84.12 & 0.001 \\
\hline ABCA12 & NM_173076 & 80.20 & 0.005 \\
\hline ClT & NM_001206999 & 63.97 & 0.000 \\
\hline SH3GL3 & NM_001301109 & 63.28 & 0.004 \\
\hline $\mathrm{KIT}$ & NM_000222 & 61.06 & 0.011 \\
\hline DPP10 & NM_001178036 & 57.54 & 0.018 \\
\hline TENM1 & NM_001163278 & 56.20 & 0.001 \\
\hline ROBO2 & NM_001290040 & 54.12 & 0.007 \\
\hline GYG2 & NM_003918 & -215.06 & 0.016 \\
\hline PKD1L2 & NM_052892 & -228.15 & 0.014 \\
\hline AZGP1 & NM_001185 & -242.01 & 0.004 \\
\hline MFAP5 & NM_003480 & -242.88 & 0.002 \\
\hline ABCA8 & NM_001288985 & -258.21 & 0.002 \\
\hline VIT & NM_053276 & -279.41 & 0.001 \\
\hline CYP4B1 & NM_001099772 & -281.41 & 0.004 \\
\hline Pl16 & NM_153370 & -306.57 & 0.004 \\
\hline HBA1 & NM_000558 & -315.48 & 0.008 \\
\hline ITLN1 & NM_017625 & -335.62 & 0.004 \\
\hline ALDH1L1 & NM_012190 & -375.76 & 0.024 \\
\hline PLIN4 & NM_001080400 & -392.80 & 0.009 \\
\hline CFD & NM_001928 & -565.13 & 0.001 \\
\hline C14orf180 & NM_001286400 & -681.24 & 0.016 \\
\hline PPP1R1A & NM_006741 & -709.72 & 0.015 \\
\hline HRASLS5 & NM_054108 & -740.50 & 0.017 \\
\hline $\mathrm{ADH} 1 \mathrm{C}$ & NM_000669 & -846.95 & 0.001 \\
\hline $\mathrm{ADH} 1 \mathrm{~B}$ & NM_001286650 & -886.39 & 0.021 \\
\hline ADH1A & NM_000667 & -969.78 & 0.003 \\
\hline TUSC5 & NM_172367 & -2204.07 & 0.025 \\
\hline
\end{tabular}

parental genes were selected for further investigation although there were some top change circRNAs in Table 2. circ_0069765, which is located on chr4 q12 (chr4:55569889-55603446), is derived from a non-coding regulatory region of KIT (Figure S2A). circ_0079471, which is located on chr7 p21.2 (chr7:13949257-13975521), is a regulatory circRNA within a long non-coding region of ETV1 (Figure S2B). However, circ_0084097 stems from a non-coding regulatory region contained a promoter blank adjacent to the promoter region of PLAT, which is located on chr8 p12 (chr8:42046451-42050729) (Figure S2C). Based on the miRNA site prediction, we predicted the targeted miRNAs of the three differential circRNAs in circular RNA Interactomem (https://circinteractome.nia.nih. gov/) (Dudekula et al., 2016). To obtain insight into reciprocal circRNA, miRNA and mRNA regulation, we constructed a regulatory circRNA-miRNA-mRNA network using Cytoscape software and clarified the interaction among the three circRNAs (circ_0069765, circ_0084097, and circ_0079471),
TABLE 2 | Partially differentially expressed circRNAs in GIST.

\begin{tabular}{|c|c|c|c|c|}
\hline circRNA_ID & $\begin{array}{l}\text { Gene bank } \\
\text { Accession No }\end{array}$ & $\begin{array}{c}\text { Fold } \\
\text { change }\end{array}$ & $p$-values & Host gene \\
\hline hsa_circ_0065978 & NM_001161581 & 598.50 & 0.020 & POC1A \\
\hline hsa_circ_0016772 & NM_001098623 & 253.92 & 0.008 & OBSCN \\
\hline hsa_circ_0016774 & NM_001098623 & 233.44 & 0.005 & OBSCN \\
\hline hsa_circ_0016775 & NM_001098623 & 231.51 & 0.004 & OBSCN \\
\hline hsa_circ_0016776 & NM_001098623 & 213.33 & 0.007 & OBSCN \\
\hline hsa_circ_0016773 & NM_001098623 & 209.56 & 0.004 & OBSCN \\
\hline hsa_circ_0016778 & NM_001098623 & 201.52 & 0.004 & OBSCN \\
\hline hsa_circ_0069236 & NM_001145847 & 184.99 & 0.006 & PROM1 \\
\hline hsa_circ_0016780 & NM_001098623 & 180.51 & 0.001 & OBSCN \\
\hline hsa_circ_0016779 & NM_001098623 & 169.85 & 0.005 & OBSCN \\
\hline hsa_circ_0023311 & NM_018043 & 137.75 & 0.001 & ANO1 \\
\hline hsa_circ_0028697 & NM_001206999 & 125.79 & 0.003 & CIT \\
\hline hsa_circ_0028694 & NM_001206999 & 124.24 & 0.000 & CIT \\
\hline hsa_circ_0028687 & NM_001206999 & 113.21 & 0.000 & CIT \\
\hline hsa_circ_0045305 & NM_138363 & 107.60 & 0.000 & CEP95 \\
\hline hsa_circ_0073782 & NM_001999 & 103.58 & 0.023 & FBN2 \\
\hline hsa_circ_0023310 & NM_018043 & 103.44 & 0.000 & ANO1 \\
\hline hsa_circ_0003570 & NM_014661 & 98.82 & 0.000 & FAM53B \\
\hline hsa_circ_0023309 & NM_018043 & 98.25 & 0.000 & ANO1 \\
\hline hsa_circ_0073792 & NM_001999 & 94.47 & 0.019 & FBN2 \\
\hline hsa_circ_0081375 & NM_001185 & -102.41 & 0.001 & AZGP1 \\
\hline hsa_circ_0037139 & NM_000517 & -105.37 & 0.020 & HBA2 \\
\hline hsa_circ_0025368 & NM_003480 & -106.22 & 0.000 & MFAP5 \\
\hline hsa_circ_0035024 & NM_001015001 & -107.93 & 0.006 & CKMT1A \\
\hline hsa_circ_0037141 & NM_000558 & -113.19 & 0.021 & HBA1 \\
\hline hsa_circ_0006751 & NM_014241 & -115.81 & 0.003 & PTPLA \\
\hline hsa_circ_0017695 & NM_024693 & -119.12 & 0.038 & ECHDC3 \\
\hline hsa_circ_0001946 & NM_004065 & -122.17 & 0.021 & CDR1 \\
\hline hsa_circ_0002091 & NM_014241 & -130.33 & 0.000 & PTPLA \\
\hline hsa_circ_0087206 & NM_000689 & -132.06 & 0.001 & ALDH1A \\
\hline hsa_circ_0005754 & NM_001103184 & -146.44 & 0.022 & FMN1 \\
\hline hsa_circ_0080888 & NM_006379 & -159.28 & 0.001 & SEMA3C \\
\hline hsa_circ_0025367 & NM_003480 & -159.49 & 0.000 & MFAP5 \\
\hline hsa_circ_0080897 & NM_006379 & -159.96 & 0.001 & SEMA3C \\
\hline hsa_circ_0048861 & NM_000064 & -181.48 & 0.004 & C3 \\
\hline hsa_circ_0048858 & NM_000064 & -182.24 & 0.006 & C3 \\
\hline hsa_circ_0048867 & NM_000064 & -182.38 & 0.007 & C3 \\
\hline hsa_circ_0048892 & NM_000064 & -196.57 & 0.010 & C3 \\
\hline hsa_circ_0048870 & NM_000064 & -218.98 & 0.005 & C3 \\
\hline hsa_circ_0048871 & NM_000064 & -279.58 & 0.004 & C3 \\
\hline
\end{tabular}

their host genes (KIT, PLAT, and ETV1) and seven predicted miRNAs (miR-144-3p, miR-1246, miR-485-3p, miR-142-3p, miR-142-5p, miR-326 and miR-324-5p), which is shown in Figure 3. In the figure, the upregulated circRNAs and their host genes are marked in red, and the downregulated miRNAs that had been reported in previous studies investigating cancer tissues are marked in green. Evidently, miR-144-3p, and miR485-3p are common target miRNAs of all three host genes (KIT, PLAT, and ETV1), and miR-142-5p is a targeted miRNA of KIT and PLAT. We also found that miR-1246 was predicted as the common targets of both circ_0069765 and circ_0084097 and their host genes (KIT and PLAT), and miR-326 was predicted as the common targets of both circ_0069765 and circ_0079471. Thus, the specific regulatory networks including the three circRNAs (circ_0069765, cir_0084097, and circ_0079471), their host genes (KIT, PLAT, and ETV1) and the three miRNAs (miR-142-5p, miR-144-3p and miR-485-3p) may be key regulators in GISTs. 
TABLE 3 | Partial DEcircRNAs and DEGs as host genes in GISTs.

\begin{tabular}{|c|c|c|c|c|c|c|}
\hline circRNA_ID & $\begin{array}{l}\text { Gene bank } \\
\text { Accession No }\end{array}$ & Fold change & $p$-values & Host gene & Fold change & $p$-values \\
\hline hsa_circ_0073782 & NM_001999 & 103.58 & 0.023 & FBN2 & 133.50 & 0.019 \\
\hline hsa_circ_0017609 & NM_006257 & 39.41 & 0.014 & PRKCQ & 92.00 & 0.001 \\
\hline hsa_circ_0028697 & NM_001206999 & 125.79 & 0.003 & CIT & 63.97 & 0.000 \\
\hline hsa_circ_0069765 & NM_000222 & 66.92 & 0.002 & $\mathrm{KIT}$ & 61.06 & 0.011 \\
\hline hsa_circ_0056201 & NM_001178036 & 43.76 & 0.047 & DPP10 & 57.54 & 0.018 \\
\hline hsa_circ_0091277 & NM_198465 & 70.33 & 0.000 & NRK & 51.90 & 0.000 \\
\hline hsa_circ_0079471 & NM_004956 & 36.48 & 0.005 & ETV1 & 45.36 & 0.009 \\
\hline hsa_circ_0008714 & NM_001025390 & 66.38 & 0.004 & AMPD3 & 33.80 & 0.003 \\
\hline hsa_circ_0071585 & NM_000892 & 5.39 & 0.023 & KLKB1 & 24.89 & 0.026 \\
\hline hsa_circ_0086362 & NM_002839 & 65.77 & 0.009 & PTPRD & 23.58 & 0.009 \\
\hline hsa_circ_0073242 & NM_004385 & 20.36 & 0.000 & VCAN & 23.06 & 0.000 \\
\hline hsa_circ_0084097 & NM_000930 & 19.09 & 0.013 & PLAT & 22.19 & 0.007 \\
\hline hsa_circ_0015753 & NM_198503 & 14.62 & 0.001 & KCNT2 & 19.19 & 0.007 \\
\hline hsa_circ_0027663 & NM_001135805 & 29.87 & 0.001 & SYT1 & 18.99 & 0.009 \\
\hline hsa_circ_0055922 & NM_201555 & 24.80 & 0.008 & $\mathrm{FHL} 2$ & 16.85 & 0.000 \\
\hline hsa_circ_0047919 & NM_152721 & 6.70 & 0.041 & DOK6 & 16.10 & 0.011 \\
\hline hsa_circ_0052028 & NM_002975 & 16.82 & 0.003 & CLEC11A & 16.07 & 0.003 \\
\hline hsa_circ_0070911 & NM_014278 & 12.28 & 0.001 & HSPA4L & 15.89 & 0.001 \\
\hline hsa_circ_0070487 & NM_005723 & 14.36 & 0.013 & TSPAN5 & 15.41 & 0.007 \\
\hline hsa_circ_0069722 & NM_145263 & 29.12 & 0.002 & SPATA18 & 14.52 & 0.001 \\
\hline hsa_circ_0080961 & NM_000927 & 25.22 & 0.019 & ABCB1 & 12.98 & 0.001 \\
\hline hsa_circ_0015816 & NM_205860 & -19.14 & 0.020 & NR5A2 & -9.17 & 0.024 \\
\hline hsa_circ_0014229 & NM_019554 & -41.00 & 0.008 & S100A4 & -10.00 & 0.003 \\
\hline hsa_circ_0033629 & NM_001311 & -13.51 & 0.007 & CRIP1 & -10.04 & 0.015 \\
\hline hsa_circ_0000895 & NM_002229 & -8.78 & 0.009 & JUNB & -10.11 & 0.007 \\
\hline hsa_circ_0070442 & NM_007351 & -31.47 & 0.003 & MMRN1 & -11.11 & 0.004 \\
\hline hsa_circ_0013276 & NM_001013660 & -9.10 & 0.001 & FRRS1 & -11.70 & 0.005 \\
\hline hsa_circ_0087214 & NM_000700 & -38.15 & 0.033 & ANXA1 & -12.81 & 0.007 \\
\hline hsa_circ_0078299 & NM_005100 & -14.43 & 0.002 & AKAP12 & -14.88 & 0.003 \\
\hline hsa_circ_0060545 & NM_002999 & -7.21 & 0.034 & SDC4 & -16.55 & 0.016 \\
\hline hsa_circ_0032974 & NM_006329 & -23.91 & 0.029 & FBLN5 & -17.26 & 0.010 \\
\hline hsa_circ_0000074 & NM_002228 & -13.85 & 0.018 & JUN & -17.69 & 0.006 \\
\hline hsa_circ_0055622 & NM_207328 & -2.59 & 0.039 & GPT2 & -18.34 & 0.002 \\
\hline hsa_circ_0046941 & NM_002071 & -5.80 & 0.043 & GNAL & -23.67 & 0.002 \\
\hline hsa_circ_0008591 & NM_053025 & -18.81 & 0.025 & MYLK & -26.71 & 0.016 \\
\hline hsa_circ_0049487 & NM_001299 & -38.06 & 0.048 & CNN1 & -28.60 & 0.041 \\
\hline hsa_circ_0070510 & NM_016242 & -23.03 & 0.038 & EMCN & -31.55 & 0.029 \\
\hline hsa_circ_0039466 & NM_175617 & -11.67 & 0.001 & MT1E & -35.88 & 0.002 \\
\hline hsa_circ_0056473 & NM_032995 & -12.44 & 0.007 & ARHGEF4 & -45.11 & 0.000 \\
\hline hsa_circ_0003625 & NM_032784 & -50.11 & 0.008 & RSPO3 & -60.82 & 0.009 \\
\hline hsa_circ_0025368 & NM_003480 & -196.57 & 0.000 & MFAP5 & -242.90 & 0.002 \\
\hline
\end{tabular}

\section{Differential circRNAs (circ_0069765, circ_0079471 and circ_0084097) and Their Host Genes Were Verified in GISTs by qRT-PCR}

The genomic structure shows that circ_0069765 contains six exons from the KIT gene (Figure S2A), circ_0079471 contains four exons from ETV1 gene (Figure S2B), and circ_0084097 contains three exons from PLAT gene (Figure S2C). All the "head-to-tail" splicing sites of the three circRNAs are presented in Figure S2. The distinct products of these three circRNAs were amplified using outward-facing primers and confirmed by Sanger sequencing (Figures S3A-C). We found that circ_0069765, circ_0079471 and circ_0084097 were resistant to RNase R, compared to the linear mRNAs (Data not shown). Next, we detected the expression level of circ_0069765, circ_0079471, circ_0084097 and their corresponding host genes by real-time PCR (qRT-PCR) analyses. The relative expression of the three circRNAs (circ_0069765, circ_0079471 and circ_0084097) was evidently upregulated in the GIST tissues compared with that in the adjacent noncancerous tissues ( $\mathrm{p}<0.001$ ); in addition, the three host genes, i.e., KIT, PLAT and ETV1, were upregulated $(\mathrm{p}<0.001)$ (Figure 4). The qRT-PCR analyses revealed that 44 of 66 (66.67\%) tumours had increased circ_0069765 (4.68fold); 60 of 65 (92.30\%) tumours had increased host gene KIT mRNA (1404.20-fold) expression; 63 of 68 (92.65\%) tumours had increased cir_0084097 expression (156.86-fold); 61 of $68(89.71 \%)$ tumours had increased host gene PLAT mRNA (462.43-fold) expression; 59 of $68(86.76 \%)$ tumours had increased circ_0079471 (118.10-fold) expression; and 62 of 

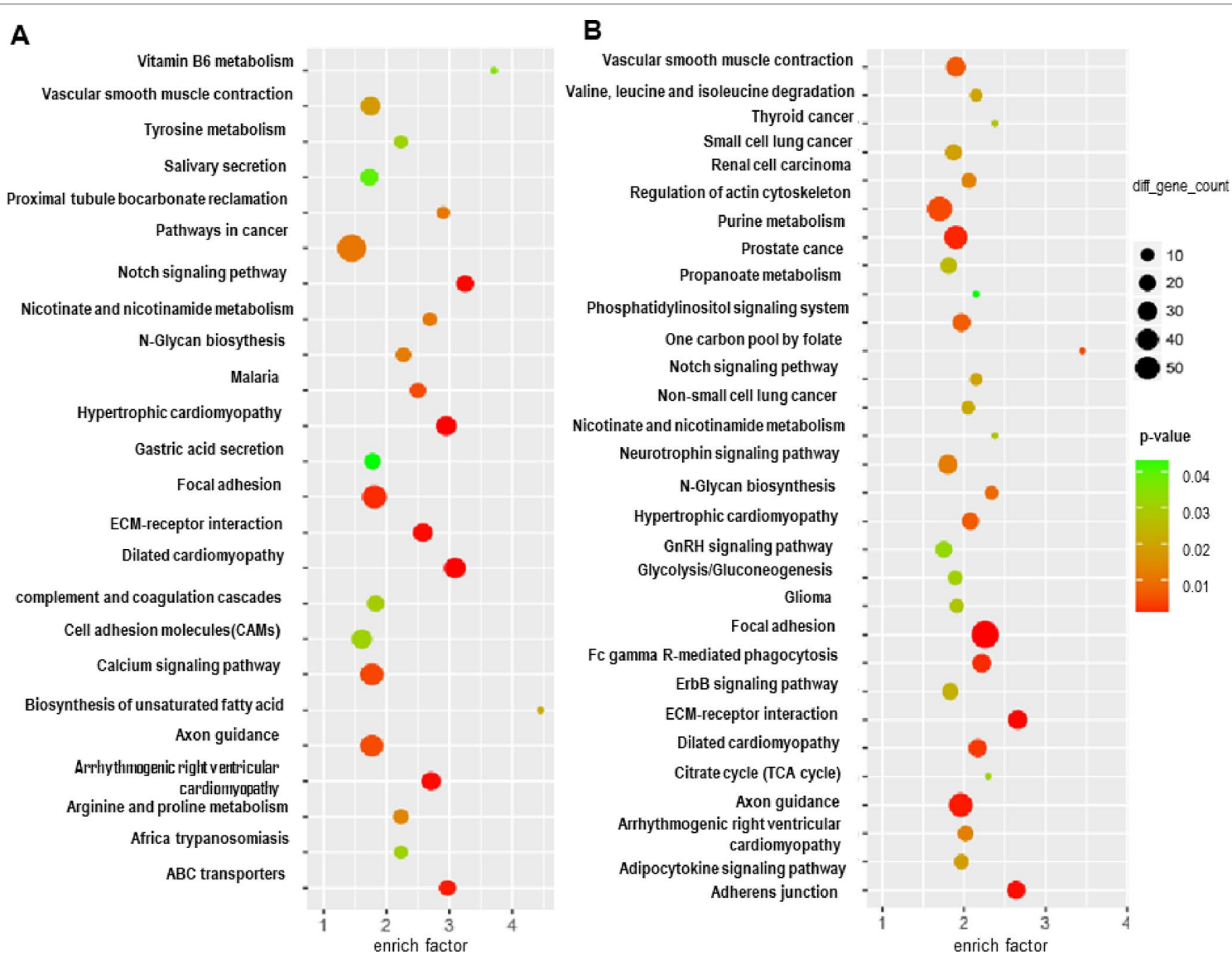

FIGURE 2 | Functional pathway analysis of targeted genes of predicted miRNAs and competitive and endogenous regulatory network. GO analysis of targeted genes (A), and KEGG analysis of targeted genes (B).

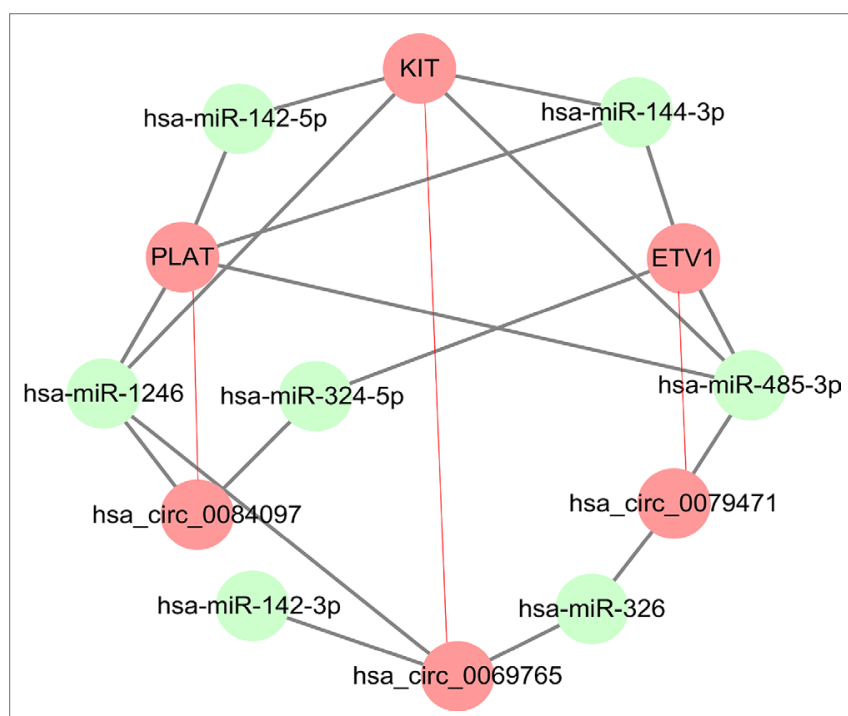

FIGURE 3 | Regulatory network analysis of DEcircRNAs, their targeted genes, and predicted miRNAs. circ_0069765, circ_0079471, circ_0084097 and their host genes (KIT, PLAT, and ETV1) in a related regulatory network.
66 (93.94\%) tumours had increased host gene ETV1 mRNA (678.60-fold) expression. These findings were consistent with the tissue microarray data and showed the significant upregulation tendency of the three circRNAs and three host genes. Finally, we identified that markable positive correlations were present between PLAT and three verified circRNAs $(\mathrm{p}<0.05)$ (Table S5). We also noted a non-negative correlation between two circRNAs and ETV1 (Table S5, ${ }^{*} \mathrm{p}<$ $0.05)$. Interestingly, an obvious correlation was observed not only between the genes ETV1 and PLAT $(\mathrm{p}<0.001)$ but also between the circRNAs circ_0069765 and circ_0079471 and between circ_0079471 and circ_0084097 ( p < 0.05) (Table S5). To clarify the characteristics of these differential circRNAs and their host genes in GIST cancer, a Pearson correlation analysis was applied to analyse the correlation between these circRNAs/their host genes and the corresponding clinical parameters. As shown in Table 4, circ_0084097 and its host gene PLAT are negatively correlated with metastasis of tumours significantly related to the stomach $(\mathrm{p}<0.05)$. PLAT was also negatively correlated with the tumour diameter $(\mathrm{p}<$ 0.05) (Table 4), indicating that circ_0084097 and PLAT may be related to the early stage of stomach stromal tumour. 


\section{A}

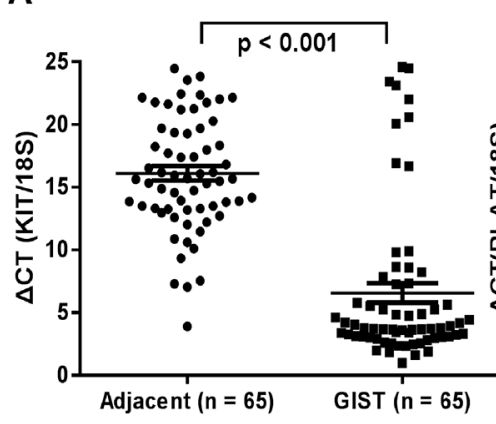

D

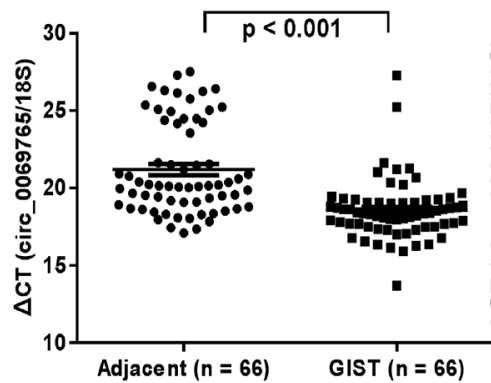

B

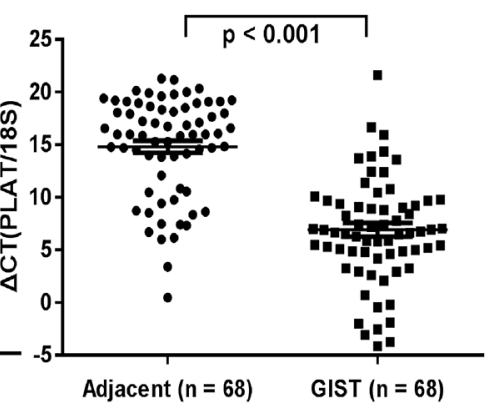

$E$

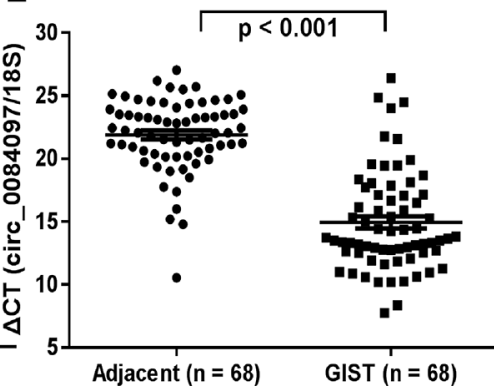

C

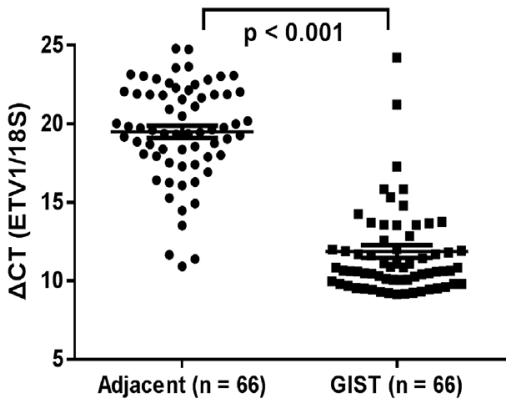

$F$

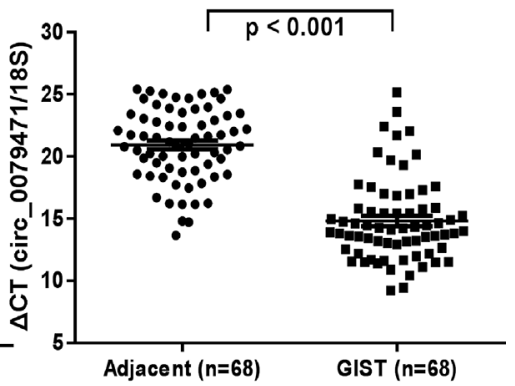

FIGURE 4 | qRT-PCR analysis of the gene expression levels of the three differentially expressed circRNAs and their host genes in GISTs. (A) KIT; (B) PLAT; (C) ETV1; (D) circ_0069765; (E) circ_0084097; and circ_0079471(F).

TABLE 4 | Correlation analysis of circ_0084097/PLAT expression in tumour tissue samples of GIST patients and their clinical factors.

\begin{tabular}{|c|c|c|c|c|c|c|c|c|}
\hline Characteristic & \multicolumn{2}{|c|}{ circ_0084097 } & $\begin{array}{l}\text { Person } \\
\text { correlation }\end{array}$ & $p$-value & \multicolumn{2}{|c|}{ PLAT } & $\begin{array}{l}\text { Person } \\
\text { correlation }\end{array}$ & p-value \\
\hline Location & & & 0.310 & 0.010 & & & 0.284 & 0.019 \\
\hline Other & 19 & 10 & & & 21 & 8 & & \\
\hline Metastasis & & & -0.246 & 0.045 & & & -0.242 & 0.049 \\
\hline Yes & 7 & 4 & & & 8 & 3 & & \\
\hline Yes & 7 & 3 & & & 7 & 3 & & \\
\hline No & 27 & 31 & & & 27 & 31 & & \\
\hline Adhesion & & & -0.1 & 0.419 & & & -0.198 & 0.106 \\
\hline Yes & 15 & 15 & & & 19 & 11 & & \\
\hline No & 19 & 19 & & & 15 & 23 & & \\
\hline $\begin{array}{l}\text { Maxium tumour } \\
\text { diameter }\end{array}$ & & & -0.059 & 0.635 & & & -0.298 & 0.013 \\
\hline low risk & 15 & 11 & & & 12 & 14 & & \\
\hline $\begin{array}{l}\text { intermediate and } \\
\text { high risk }\end{array}$ & 19 & 23 & & & 22 & 20 & & \\
\hline
\end{tabular}

Bold values denote statistical significance at the $p<0.05$ level.

\section{DISCUSSION}

In this study, the ceRNA expression profile showed that the mRNA and circRNA expression profile in the gastric stromal tumour tissues was distinguished from that in matched tissues adjacent to the tumour and found that a total of 3,122 circRNAs were significantly upregulated and 2,648 were significantly downregulated in the tumour tissues. More importantly, 95 differentially expressed genes had been filtered by overlapping circRNA host genes and significant mRNAs of GSE112. We found several common pathways involving the differential mRNAs and the host genes of differential circRNAs in GISTs, including vascular smooth muscle contraction, Notch 
signalling pathway, nicotinate and nicotinamide metabolism, N-Glycan biosynthesis, Hypertrophic cardiomyopathy (HCM), Focal adhesion, ECM-receptor interaction, Dilated cardiomyopathy, Axon guidance, and Arrhythmogenic right ventricular cardiomyopathy (ARVC) (Figure 2). Three molecular inhibitors of the Wnt signalling pathway have been reported to be tumour suppressors in various in vitro and in vivo GIST models harbouring a KIT mutation. The Wnt antagonist DKK4 was apparently downregulated in advanced human GISTs (Zeng et al., 2017). The Notch signalling pathway has also been reported to be a tumour suppressor in GIST cells harbouring a KIT mutation. The downstream target of notch (dominant-negative Hes1) was apparently upregulated in GIST patients with longer relapse-free survival (Yang et al., 2018). In addition, the focal adhesion signalling pathway played a critical role in the proliferation of both imatinib-sensitive and resistant GIST cells (Zeng et al., 2017). We demonstrated that the Wnt, Notch and Focal adhesion signalling pathways are associated with GIST cell proliferation.

Notably, 95 genes were not only differentially expressed linear RNAs but also maternal genes that generated various differentially expressed circular RNAs in our study. circ_0069765, circ_0079471 and circ_0084097 were selected for the validation of the array results, and we detected the expression of these circRNAs in 68 pairs of tissue samples and showed that the three circRNAs were significantly upregulated in tumour tissues, while their host genes KIT, PLAT and ETV1 had a similar rising trend in expression. Furthermore, the expression levels of these three circRNAs and their host genes were also checked in GIST cell lines. We only found that circ_0069765 was significantly upregulated in the GIST-T1 and GIST-882 cells and that circ_0079471 and its host gene ETV1 were overexpressed in the GIST-T1 cells compared to the normal stomach stromal tissue by a qRT-PCR analysis (all $\mathrm{p}<0.05)$ (Figure S4).

Web tools for miRNA target-site prediction for circRNA that have a sequence-based recognition system come with the context scores which have the advantage of being predictive for all types of interactions. There is not standard score for selecting top miRNAs. We selected top miRNAs with the high context score (score $>85$ ) for the three differential circRNAs to establish a circRNA-miRNA-host gene network in GIST (Table S6) and found that miR-142-3p, miR-142-5p, miR149, miR-324-5p, miR-326, miR-485-3p and miR-1246 might interact with circ_0069765, circ_0079471 and circ_0084097. Interestingly, miR-1246, miR-142-5p, and miR-324-5p were downregulated in the GIST cells (GIST-882 and GIST-T1)
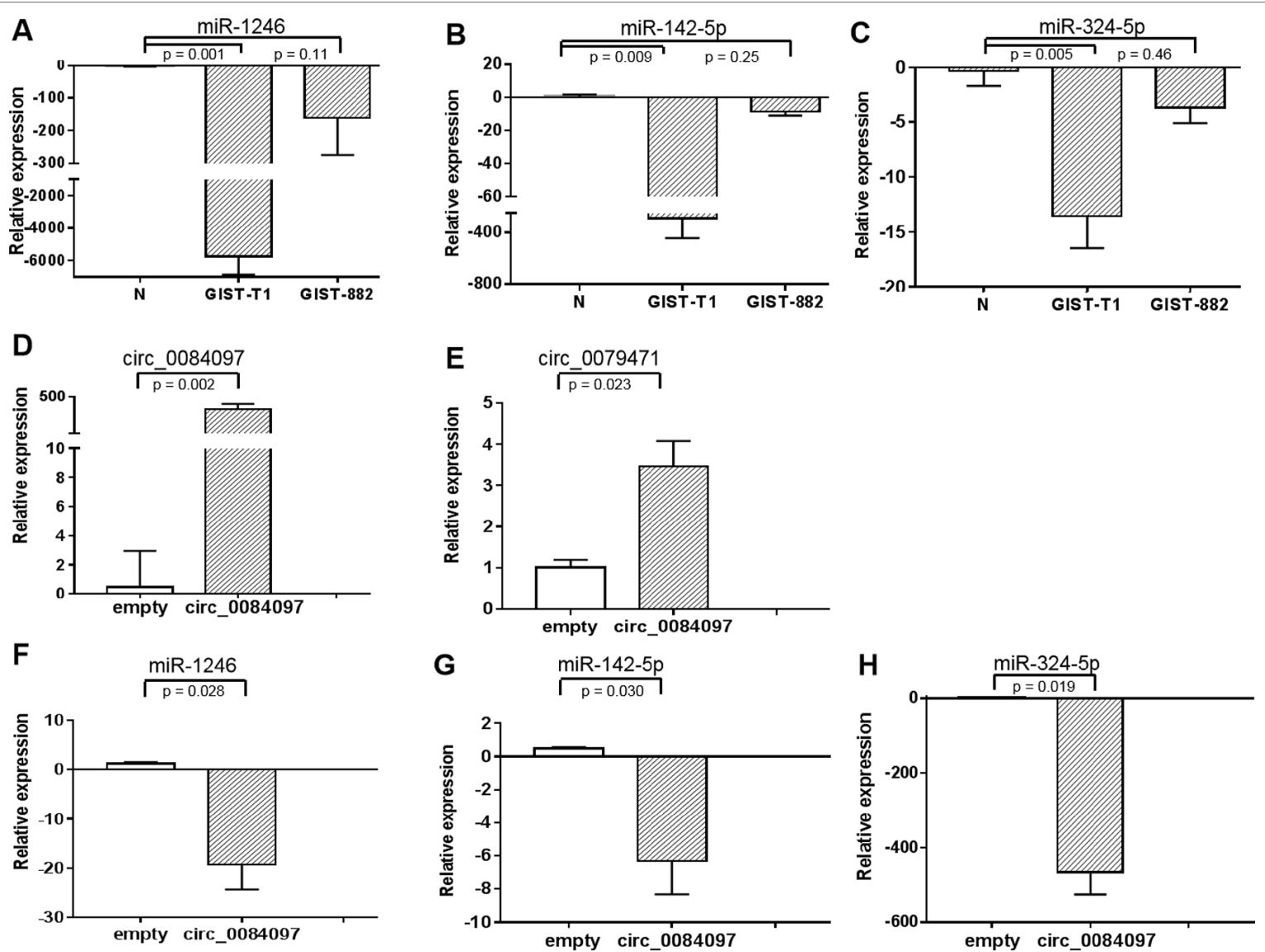

FIGURE 5 | Gene expression levels of miR-1246, miR-142-5p, and miR-324-5p in GIST-T1 and GIST-882 cells (A-C) (A) miR-1246; (B) miR-142-5p; (C) miR-324-5p and their expression in GIST-T1 with circ_0079471 by overexpression of circ_0084097 (D-H) (D) circ_0084097; (E) circ_0079471; (F) miR-1246; (G) miR-142-5p; (H) miR-324-5p were analysed by qRT-PCR. 
compared to the normal stomach stromal tissue in the qRTPCR analysis (Figures 5A-C). In the analysis of the function of the ceRNAs and their interaction, we confirmed that these three miRNAs were also repressed and that circ_0079471 was upregulated in GIST-T1 cells by overexpression of circ_0084097 (Figures 5D-H), which was consistent with our circRNA-miRNA regulatory network analysis in GISTs (Figure 4). Thus, these miRNAs may be linked to several host genes, including KIT, PLAT, and ETV1. In GISTs, a KIT proximal domain mutation, especially in exon 11, can induce ligandindependent kinase phosphorylation and activate downstream signal transduction pathway, including AKT, MAPK and STAT (Corless et al., 2011). The molecular targeted agent, Imatinib, blocks KIT / PDGFRA signalling by binding the ATP-binding pocket required for phosphorylation and activation of the receptor. The application of imatinib had changed from a single drug model to a combination with surgical treatment, which was essential to complete surgical resection, alleviate the disease, prolong survival and improve the quality of life, especially among postoperative patients (Huang et al., 2016). Unfortunately, initially sensitive tumours acquired imatinib resistance due to a KIT secondary mutation. Sunitinib and regorafenib are two additional multikinase inhibitors approved as second- and third-line therapies, respectively, and are available for the treatment of imatinib-resistance GIST (Demetri et al., 2006; Demetri et al., 2013). It has been found that non-small cell lung cancer tumourigenesis was suppressed by the overexpression of miR142-5p, which also regulated tumour cell PD-L1 expression and enhanced anti-tumour immunity in pancreatic cancer (Jia et al., 2017; Wang et al., 2017a). The downregulation of miR-142-5p was significantly associated with the recurrence and poor prognosis of gastric cancer (GC) and promoted tumour metastasis by regulating CYR61 expression (Yan et al., 2019). miR-144-3p was significantly downregulated in hepatocellular carcinoma, glioblastoma, multiple myeloma and pancreatic cancer and inhibited proliferation, migration and tumour metastasis by targeting SGK3 (Wu et al., 2017), FZD7 (Cheng et al., 2017), c-Met (Zhao et al., 2017) and FOSB (Liu et al., 2018). The repression of miR485-3p was also found in breast cancer. The overexpression of miR-485-3p can inhibit mitochondrial respiration and breast cancer cell metastasis by inhibiting PGC-1 $\alpha$ expression (Lou et al., 2016). Low serum levels of miR-485-3p were related to poor survival in patients with glioblastoma (Wang et al., 2017b). The miR-324-5p-mediated suppression of NF- $\kappa B$ activation was reported to be responsible for inhibition breast cancer cell invasion and migration (Song et al., 2015). The expression of miR-1246 was downregulated in lung cancer cell lines and cervical cancer tissue, was negatively correlated with the clinical stage and inhibited cell invasion and the EMT by targeting CXCR4 (Yang et al., 2015; Xu et al., 2018). miR149 was downregulated in ovarian cancer, colorectal cancer and lung cancer. The overexpression of miR-149 increased the drug sensitivity of cancer cells and inhibited the EMT through the FOXM1/cyclin D1/MMP2 axis (Ke et al., 2013; Xu et al., 2015; Sun et al., 2018). Thus, the decreased expression and functional inhibition of these miRNAs in cancer further support our hypothesis that circ_0069765, circ_0079471 and circ_0084097 function to regulate the more comprehensive circRNAs-miRNAs-genes network.

In summary, the present research revealed the ceRNA expression profiles in GISTs and identified that three circRNAs (circ_0069765, circ_0079471 and circ_0084097) and three host genes (KIT, ETV1 and PLAT) were upregulated in GISTs using qRT-PCR. We further demonstrated that the specific regulatory networks including three circRNAs (circ_0069765, cir_0084097, and circ_0079471), their host genes (KIT, PLAT, and ETV1) and three miRNAs (miR-142-5p, miR-144-3p and miR-485-3p) may be key regulators in GISTs and are likely involved in tumour oncogenesis and progression. In future investigations, it is worth considering the verification of the molecular mechanism of these specific circRNAs to regulate GIST occurrence and development. A greater understanding of the mechanisms of the involvement of specific circRNAs in GIST tumour malignancy is necessary for the identification of possible therapeutic targets.

\section{DATA AVAILABILITY}

The datasets generated for this study can be found at NCBI using accession number GSE131481 (https://www.ncbi.nlm.nih.gov/ geo/query/acc.cgi? acc=GSE131481).

\section{ETHICS STATEMENT}

The study included patients with GIST who underwent partial or complete resection at Shanghai Public Health Clinical Center, Fudan University, China between Sept 2016 and Oct 2017. The study was approved by the Medical Ethics Commission of Shanghai Public Health Clinical Center.

\section{AUTHOR CONTRIBUTIONS}

JW and HT contributed to the conception; NJ, HT, YZ, HK, YW, WL, SZ, and JW analyzed the data; NJ and JW wrote the manuscript; and JW revised the manuscript.

\section{FUNDING}

This research was supported by a grant from the National Natural Science Foundation of China (81672383), the National Special Research Program of China for Important Infectious Diseases (2018ZX10302103-003). The grant (KY-GW-2017-09) (HT) was from Shanghai Public Health Clinical Center, Shanghai, China.

\section{SUPPLEMENTARY MATERIAL}

The Supplementary Material for this article can be found online at: https://www.frontiersin.org/articles/10.3389/fgene.2019.00825/ full\#supplementary-material 


\section{REFERENCES}

Cheng, Z. X., Song, Y. X., Wang, Z. Y., Wang, Y., and Dong, Y. (2017). miR144-3p serves as a tumor suppressor by targeting FZD7 and predicts the prognosis of human glioblastoma. Eur. Rev. Med. Pharmacol. Sci. 21, 4079-4086.

Chi, P., Chen, Y., Zhang, L., Guo, X., Wongvipat, J., Shamu, T., et al. (2010). ETV1 is a lineage survival factor that cooperates with KIT in gastrointestinal stromal tumours. Nature 467, 849-853. doi: 10.1038/nature09409

Corless, C. L., Barnett, C. M., and Heinrich, M. C. (2011). Gastrointestinal stromal tumours: origin and molecular oncology. Nat. Rev. Cancer 11, 865-878. doi: $10.1038 / \mathrm{nrc} 3143$

Corless, C. L., Fletcher, J. A., and Heinrich, M. C. (2004). Biology of gastrointestinal stromal tumors. J. Clin. Oncol. 22, 3813-3825. doi: 10.1200/ JCO.2004.05.140

Fletcher, C. D., Berman, J. J., Corless, C., Gorstein. F., Lasota, J., Longley, B. J., et al. (2002). Diagnosis of gastrointestinal stromal tumors: a consensus approach. Hum. Pathol. 33. doi: 10.1053/hupa.2002. 124119

Demetri, G. D., van Oosterom, A. T., Garrett, C. R., Blackstein, M. E., Shah, M. H., Verwei, J., et al. (2006). Effi cacy and safety of sunitinib in patients with advanced gastrointestinal stromal tumour after failure of imatinib: a randomised controlled trial. Lancet 368, 1329-1338. doi: 10.1016/ S0140-6736(06)69446-4

Demetri, G. D., Reichardt, P., Kang, Y. K., Blay, J. Y., Rutkowski, P., Gelderblom, H., et al. (2013). Effi cacy and safety of regorafenib for advanced gastrointestinal stromal tumours after failure of imatinib and sunitinib (GRID): an international, multicentre, randomised, placebo-controlled, phase 3 trial. Lancet 381, 295-302. doi: 10.1016/S0140-6736(12)61857-1

Dudekula, D. B., Panda, A. C., Grammatikakis, I., De, S., Abdelmohsen, K., and Gorospe, M. (2016). CircInteractome: a web tool for exploring circular RNAs and their interacting proteins and microRNAs. RNA Biol. 13, 34-42. doi: $10.1080 / 15476286.2015 .1128065$

Duensing, A. (2015). Targeting ETV1 in gastrointestinal stromal tumors: tripping the circuit breaker in GIST? Cancer Discov. 5, 231-233. doi: 10.1158/21598290.CD-15-0116

Gao, Y., and Zhao, F. (2018). Computational strategies for exploring circular RNAs. Trends Genet. 34, 389-400. doi: 10.1016/j.tig.2017.12.016

Heinrich, M. C., Corless, C. L., Duensing, A., Mcgreevey, L., Chen, C. J., Joseph, N., et al. (2003b). PDGFRA activating mutations in gastrointestinal stromal tumors. Science 299,708-710. doi: 10.1126/science.1079666

Heinrich, M. C., Corless, C. L., Demetri, G. D., Blanke, C. D., Von Mehren, M., Joensuu, H., et al. (2003a). Kinase mutations and imatinib response in patients with metastatic gastrointestinal stromal tumor. J. Clin. Oncol. 21, 4342-4349. doi: 10.1200/JCO.2003.04.190

Hirota, S., Isozaki, K., Moriyama, Y., Hashimoto, K., Nishida, T., Ishiguro, S., et al. (1998). Gain-of-function mutations of c-kit in human gastrointestinal stromal tumors. Science 279, 577-580. doi: 10.1126/science.279.5350.577

Ho, M. Y., and Blanke, C. D. (2011). Gastrointestinal stromal tumors: disease and treatment update. Gastroenterology 140, 1372-1376, e1372. doi: 10.1053/j. gastro.2011.03.017

Huang, K. K., Mcpherson, J. R., and Tay, S. T. (2016). SETD2 histone modifier loss in aggressive GI stromal tumours. Gut 65, 1960-1972. doi: 10.1136/ gutjnl-2015-309482

Jia, L., Xi, Q., Wang, H., Zhang, Z., Liu, H., Cheng, Y., et al. (2017). miR-142-5p regulates tumor cell PD-L1 expression and enhances anti-tumor immunity. Biochem. Biophys. Res. Commun. 488, 425-431. doi: 10.1016/j.bbrc.2017.05.074

Joensuu, H. (2008). Risk stratification of patients diagnosed with gastrointestinal stromal tumor. Hum. Pathol. 39, 1411-1419. doi: 10.1016/j.humpath.2008.06.025

Joensuu, H., Vehtari, A., Riihimäki, J., Nishida, T., Steigen, S. E., Brabec, P., et al. (2012). Risk of recurrence of gastrointestinal stromal tumour after surgery: an analysis of pooled population-based cohorts. Lancet Oncol. 13, 265-274. doi: 10.1016/S1470-2045(11)70299-6

Ke, Y., Zhao, W., Xiong, J., and Cao, R. (2013). miR-149 inhibits non-small-cell lung cancer cells EMT by targeting FOXM1. Biochem. Res. Int. 2013, 506731. doi: 10.1155/2013/506731

Kim, H. H., Kuwano, Y., Srikantan, S., Lee, E. K., Martindale, J. L., and Gorospe, M. (2009). HuR recruits let-7/RISC to repress c-Myc expression. Genes Dev. 23, 1743-1748. doi: 10.1101/gad.1812509
Li, F., Zhang, L., Lu, J., Li, W., and Zhou, Y. (2015). Circular RNA ITCH has inhibitory effect on ESCC by suppressing the Wnt/ $\beta$-catenin pathway. Oncotarget 6, 6001-6013. doi: 10.18632/oncotarget.3469

Li, J., Yang, J., Zhou, P., Le, Y., Zhou, C., Wang, S., et al. (2015). Circular RNAs in cancer: novel insights into origins, properties, functions and implications. Am. J. Cancer Res. 5, 472-480.

Liu, S., Luan, J., and Ding, Y. (2018). miR-144-3p Targets FosB Proto-oncogene, AP-1 Transcription Factor Subunit (FOSB) to suppress proliferation, migration, and invasion of PANC-1 pancreatic cancer cells. Oncol. Res. 26, 683-690. doi: 10.3727/096504017X14982585511252

Lou, C., Xiao, M., Cheng, S., Lu, X., Jia, S., Ren, Y., et al. (2016). MiR-485-3p and miR-485-5p suppress breast cancer cell metastasis by inhibiting PGC-1alpha expression. Cell Death Dis. 7, e2159. doi: 10.1038/cddis.2016.27

Ma, N., Xu, H., Zhou, Y., Liu, M., Wei Zhou, J., and Jie Wang, C. (2018). Analyzing the molecular mechanism of the tissue specificity of gastrointestinal stromal tumors by using bioinformatics approaches. J. Buon. 23, 1149-1155.

Markku Miettinen, M., and Jerzy Lasota, M. (2006). Gastrointestinal stromal tumors: Pathology and prognosis at different sites. Semin. Diagn. Pathol. 23, 70-83. doi: 10.1053/j.semdp.2006.09.001

Mazur, M. T., and Clark, H. B. (1983). Gastric stromal tumors: reappraisal of histogenesis. Am. J. Surg. Pathol. 7, 507-519. doi: 10.1097/00000478-1983090 00-00001

Patop, I. L., and Kadener, S. (2018). circRNAs in Cancer. Curr. Opin. Genet. Dev. 48, 121-127. doi: 10.1016/j.gde.2017.11.007

Song, L., Liu, D., Zhao, Y., He, J., Kang, H., Dai, Z., et al. (2015). Sinomenine inhibits breast cancer cell invasion and migration by suppressing NF-kappaB activation mediated by IL-4/miR-324-5p/CUEDC2 axis. Biochem. Biophys. Res. Commun. 464, 705-710. doi: 10.1016/j.bbrc.2015.07.004

Soreide, K., Sandvik, O. M., Soreide, J. A., Giljaca, V., Jureckova, A., and Bulusu, V. R. (2016). Global epidemiology of gastrointestinal stromal tumours (GIST): a systematic review of population-based cohort studies. Cancer Epidemiol. 40, 39-46. doi: 10.1016/j.canep.2015.10.031

Sun, L., Zhai, R., Zhang, L., and Zhao, S. (2018). MicroRNA-149 suppresses the proliferation and increases the sensitivity of ovarian cancer cells to cisplatin by targeting X-linked inhibitor of apoptosis. Oncol. Lett. 15, 7328-7334. doi: 10.3892/ol.2018.8240

Suzuki, H., Zuo, Y., Wang, J., Zhang, M. Q., Malhotra, A., and Mayeda, A. (2006). Characterization of RNase R-digested cellular RNA source that consists of lariat and circular RNAs from pre-mRNA splicing. Nucleic Acids Res. 34, e63. doi: $10.1093 / \mathrm{nar} / \mathrm{gkl1} 151$

Wang, Z., Liu, Z., Fang, X., and Yang, H. (2017a). MiR-142-5p suppresses tumorigenesis by targeting PIK3CA in non-small cell lung cancer. Cell Physiol. Biochem. 43, 2505-2515. doi: 10.1159/000484459

Wang, Z. Q., Zhang, M. Y., Deng, M. L., Weng, N. Q., Wang, H. Y., and Wu, S. X. (2017b). Low serum level of miR-485-3p predicts poor survival in patients with glioblastoma. PLoS One 12, e0184969. doi: 10.1371/journal. pone. 0184969

Wilusz, J. E. (2017). Circular RNAs: unexpected outputs of many protein-coding genes. RNA Biol. 14, 1007-1017. doi: 10.1080/15476286.2016.1227905

Wilusz, J. E. (2018). A 360 degrees view of circular RNAs: from biogenesis to functions. Wiley Interdiscip. Rev. RNA 9, e1478. doi: 10.1002/wrna.1478

Wozniak, A., Rutkowski, P., Piskorz, A., Ciwoniuk, M., Osuch, C., Bylina, E., et al. (2012). Prognostic value of KIT/PDGFRA mutations in gastrointestinal stromal tumours (GIST): Polish Clinical GIST Registry experience. Ann. Oncol. 23, 353-360. doi: 10.1093/annonc/mdr127

Wu, C. E., Tzen, C. Y., Wang, S. Y., and Yeh, C. N. (2019). Clinical diagnosis of Gastrointestinal Stromal Tumor (GIST): from the molecular genetic point of view. Cancers (Basel) 11, Pii: E679. doi: 10.3390/cancers11050679

Wu, M., Huang, C., Huang, X., Liang, R., Feng, Y., and Luo, X. (2017). MicroRNA-144-3p suppresses tumor growth and angiogenesis by targeting SGK3 in hepatocellular carcinoma. Oncol. Rep. 38, 2173-2181. doi: $10.3892 / o r .2017 .5900$

Xia, Q., Ding, T., Zhang, G., Li, Z., Zeng, L., Zhu, Y., et al. (2018). Circular RNA expression profiling identifies prostate cancer-specific circRNAs in prostate cancer. Cell Physiol. Biochem. 50, 1903-1915. doi: $10.1159 / 000494870$

Xu, K., Liu, X., Mao, X., Xue, L., Wang, R., Chen, L., et al. (2015). MicroRNA-149 suppresses colorectal cancer cell migration and invasion by directly targeting 
forkhead box transcription factor FOXM1. Cell Physiol. Biochem. 35, 499-515. doi: $10.1159 / 000369715$

Xu, X., Cao, L., Zhang, Y., Lian, H., Sun, Z., and Cui, Y. (2018). MicroRNA-1246 inhibits cell invasion and epithelial mesenchymal transition process by targeting CXCR4 in lung cancer cells. Cancer Biomark 21, 251-260. doi: 10.3233/CBM-170317

Yan, J., Yang, B., Lin, S., Xing, R., and Lu, Y. (2019). Downregulation of miR$142-5 p$ promotes tumor metastasis through directly regulating CYR61 expression in gastric cancer. Gastric Cancer. 22, 302-313. doi: 10.1007/ s10120-018-0872-4

Yang, C., Yuan, W., Yang, X., Li, P., Wang, J., Han, J., et al. (2018). Circular RNA circ-ITCH inhibits bladder cancer progression by sponging miR-17/miR224 and regulating p21, PTEN expression. Mol. Cancer, 17,19. doi: 10.1186/ s12943-018-0771-7

Yang, Y., Xie, Y. J., Xu, Q., Chen, J. X., Shan, N. C., and Zhang, Y. (2015). Down-regulation of miR-1246 in cervical cancer tissues and its clinical significance. Gynecol. Oncol. 138, 683-688. doi: 10.1016/j. ygyno.2015.06.015
Zeng, S., Seifert, A. M., Zhang, J. Q., Cavnar, M. J., Kim, T. S., Balachandran, V. P., et al. (2017). Wnt/beta-catenin signaling contributes to tumor malignancy and is targetable in gastrointestinal stromal tumor. Mol. Cancer Ther. 16, 19541966. doi: 10.1158/1535-7163.MCT-17-0139

Zhao, Y., Xie, Z., Lin, J., and Liu, P. (2017). MiR-144-3p inhibits cell proliferation and induces apoptosis in multiple myeloma by targeting c-Met. Am. J. Transl. Res. 9, 2437-2446.

Conflict of Interest Statement: The authors declare that the research was conducted in the absence of any commercial or financial relationships that could be construed as a potential conflict of interest.

Copyright (๑) 2019 Jia, Tong, Zhang, Katayama, Wang, Lu, Zhang and Wang. This is an open-access article distributed under the terms of the Creative Commons Attribution License (CC BY). The use, distribution or reproduction in other forums is permitted, provided the original author(s) and the copyright owner(s) are credited and that the original publication in this journal is cited, in accordance with accepted academic practice. No use, distribution or reproduction is permitted which does not comply with these terms. 